\title{
A complete mitochondrial genome sequence of the wild two-humped camel (Camelus bactrianus ferus): an evolutionary history of camelidae
}

\author{
Peng Cui ${ }^{\dagger 2,3}$, Rimutu Ji ${ }^{\dagger 1}$, Feng Ding ${ }^{2,3}$, Dan $\mathrm{Qi}^{2,3}$, Hongwei Gao ${ }^{4}$, He Meng ${ }^{4}$, \\ Jun $\mathrm{Yu}^{2}$, Songnian $\mathrm{Hu}^{* 2}$ and Heping Zhang*1
}

Address: ${ }^{1}$ Key Laboratory of Dairy Biotechnology and Engineering Ministry of Education, College of Food Science and Engineering, Inner Mongolia Agricultural University, Huhhot, China, ${ }^{2}$ Key Laboratory of Genome Information and Sciences, Beijing Institute of Genomics, Chinese Academy of Sciences, Beijing, China, ${ }^{3}$ Graduated School of the Chinese Academy of Sciences, Beijing, China and ${ }^{4}$ School of Agriculture and biology, Shanghai Jiao Tong University, Shanghai, China

Email: Peng Cui - cuipeng@genomics.org.cn; Rimutu Ji - yeluotuojirimutu@yahoo.com.cn; Feng Ding - dingf@genomics.org.cn; Dan Qi - qid@genomics.org.cn; Hongwei Gao - gaohongwei998@sjtu.edu.cn; He Meng - menghe@sjtu.edu.cn; Jun Yu - junyu@genomics.org.cn; Songnian Hu* - husn@genomics.org.cn; Heping Zhang* - hepingdd@vip.sina.com

* Corresponding authors †Equal contributors

Published: 18 July 2007

BMC Genomics 2007, 8:24I doi:10.1|86/147|-2|64-8-24|
Received: 17 March 2007

Accepted: 18 July 2007

This article is available from: http://www.biomedcentral.com/I47I-2164/8/24I

(C) 2007 Cui et al; licensee BioMed Central Ltd.

This is an Open Access article distributed under the terms of the Creative Commons Attribution License (http://creativecommons.org/licenses/by/2.0), which permits unrestricted use, distribution, and reproduction in any medium, provided the original work is properly cited.

\begin{abstract}
Background: The family Camelidae that evolved in North America during the Eocene survived with two distinct tribes, Camelini and Lamini. To investigate the evolutionary relationship between them and to further understand the evolutionary history of this family, we determined the complete mitochondrial genome sequence of the wild two-humped camel (Camelus bactrianus ferus), the only wild survivor of the Old World camel.

Results: The mitochondrial genome sequence (16,680 bp) from C. bactrianus ferus contains 13 proteincoding, two rRNA, and 22 tRNA genes as well as a typical control region; this basic structure is shared by all metazoan mitochondrial genomes. Its protein-coding region exhibits codon usage common to all mammals and possesses the three cryptic stop codons shared by all vertebrates. $C$. bactrianus ferus together with the rest of mammalian species do not share a triplet nucleotide insertion (GCC) that encodes a proline residue found only in the $n d l$ gene of the New World camelid Lama pacos. This lineagespecific insertion in the L. pacos mtDNA occurred after the split between the Old and New World camelids suggests that it may have functional implication since a proline insertion in a protein backbone usually alters protein conformation significantly, and nd I gene has not been seen as polymorphic as the rest of ND family genes among camelids. Our phylogenetic study based on complete mitochondrial genomes excluding the control region suggested that the divergence of the two tribes may occur in the early Miocene; it is much earlier than what was deduced from the fossil record (II million years). An evolutionary history reconstructed for the family Camelidae based on cytb sequences suggested that the split of bactrian camel and dromedary may have occurred in North America before the tribe Camelini migrated from North America to Asia.
\end{abstract}

Conclusion: Molecular clock analysis of complete mitochondrial genomes from $C$. bactrianus ferus and $L$. pacos suggested that the two tribes diverged from their common ancestor about 25 million years ago, much earlier than what was predicted based on fossil records. 


\section{Background}

The family Camelidae has two Old World (tribe Camelina) species, bactrian camel (Camelus bactrianus) and dromedary (C. dromedaries), and four New World (tribe Lamini) species, guanaco (Lama guanicoe), llama ( $L$. glama), alpaca (L. pacos) and vicuna (L. vicugna or Vicugna vicugna) at present time $[1,2]$. The wild bactrian camel $(C$. bactrianus ferus) appears to be the only wild survivor of the Old World camel. According to the fossil record, Camelidae evolved in North America during the Eocene, approximately 40-45 million years ago [2], and the division between Camelini and Lamini occurred in North America about 11 million years ago $[3,4]$. In the late Tertiary (the epoch Pliocene) the species of Camelini and Lamini migrated from North America to South America and Asia separately, and their ancestors became extinct in North America subsequently. However, there have been very few molecular studies due to difficulties in either obtaining enough DNA samples or acquiring enough sequence information. Previous molecular studies, mainly focusing on the sequence of mitochondrial cytochrome $b$ gene, have made significant contributions to understanding the evolutionary history of Camelidae [2], and yet there has not been any significant comparative studies on the evolutionary relationship between Camelini and Lamini.

Mitochondrial DNA (mtDNA) has been proven useful for studying evolutionary relationships among animal species, due to its conservativeness in protein-coding sequences, high substitution rate in its non-coding sequences, and lack of genetic recombination $[5,6]$. To investigate the evolutionary relationship between Camelini and Lamini, we have made an unprecedented effort to obtain adequate samples from the wild twohumped camel, sequenced its mitochondrial genome completely, and carried out detailed sequence and evolutionary analyses.

\section{Results}

\section{Genome organization}

Since mammalian mitochondrial genome sequences are very similar, we designed a set of PCR primers based on highly conserved sequences of an alignment with fulllength mitochondrial genomes from the available public data, including those of cow, deer, sheep, pig, and lama (Table 1). We sequenced some of the PCR-amplified DNA segments first to obtain as much authentic sequences as possible from the wild two-humped camel, and subsequently designed new primers according to the newly acquired sequences. We collected 119 raw sequence traces with an average length of $521 \mathrm{bp}$ at a quality value of Q20, which cover the entire genome four folds.

The full-length mitochondrial genome is $16,680 \mathrm{bp}$ in length [GenBank: EF212038], which is 28 bp longer than that of $L$. pacos. The minor length variation mainly occurred in the tandem repeat (ACGTAC) ${ }_{n}$ of the control region. The gene order and content are identical to those of other mammals (Figure 1); it harbors 13 protein-coding genes (three subunits of the cytochrome c oxidase, seven subunits of the NADH ubiquinone oxidoreductase complex, one subunit of the ubiquinol cytochrome b oxidoreductase complex, and two subunits of ATP synthases), the small and large ribosomal RNA genes, and 22 tRNA genes (Table 2). The replication origin of the light strand within a tRNA gene cluster was also unambiguously identified.

\section{Protein-coding genes}

We carefully annotated 13 protein-coding genes (Table 2 ), including start and stop codons (ten ATGs, three ATAs, seven TAAs, two TAGs, and one AGA). Three of them, cox3,nd3, and $n d 4$, do not have normal stop codons but have the cryptic components, $\mathrm{T}, \mathrm{TA}$, and $\mathrm{T}$, respectively. The possession of such noncanonical start and stop codons is shared by most of the vertebrate mitochondrial genomes. These T or TA stop codon components are supplemented via posttranscriptional polyadenylation later in the cellular translation process [7]. Another common feature among vertebrate mitochondrial genomes is the existence of overlapping genes; for instance, ATP6 and ATP8 share a 42-bp sequence.

The mitochondrial genome of the wild camel shares its genetic code with other vertebrates (Table 3 ). In this mtDNA, the codon CTA for leucine is the most frequently used (277 times) and the codon CGT for arginine is the least frequently found ( 7 times) even though both amino acids are separately encoded by six and four codons in the canonical genetic code. The codons ending with $\mathrm{A}$ or $\mathrm{T}$ are used more frequently than those ending with $\mathrm{G}$ or $\mathrm{C}$ since it has a high $\mathrm{A}+\mathrm{T}(57.9 \%)$ content similar to what have been found among other mammals.

\section{Transfer RNA genes}

We identified 22 tRNA genes in mtDNA of the wild camel; 21 of them were predicted capable of folding into the cloverleaf structure and possess anticodons that match the vertebrate mitochondrial genetic code (Figure 2A). Only one of them, tRNA ${ }^{\text {ser }}$ lacks the appropriate sequence elements for forming an orthodox cloverleaf structure as well as both dihydrouridine loop and the anticodon (Figure $2 \mathrm{~B})$. Although it has been predicted that this tRNA ${ }^{\text {ser }}$ gene (for AGN) may be a pseudogene as observed among other metazoan mitochondrial genomes and some of them were proven inactive [8], efforts have been made to uncover underlying molecular details as to how serine residues are actually added into peptide chains with this "bizarre" tRNA [9]. 
Table I: PCR primers used for the experiment

\begin{tabular}{lll}
\hline Primer & Sequence(5' $\left.-3^{\prime}\right)$ & Strand \\
\hline $12 s-\left.12\right|^{a}$ & GGAGCTGGTATCAAGCAC & upper \\
$12 s-942$ & CAGTATGCTTACCTTGTTAC & lower \\
$16 s-136$ & GCTATAGAGAAAGTACCGTAAG & upper \\
$16 \mathrm{~s}-648$ & CTCATATTAACATTATTGCTTC & lower \\
$16 \mathrm{~s}-1053$ & ACTGTCTCTTACTTCCAATC & upper \\
$16 \mathrm{~s}-1478$ & ATAGATAGAAACCGACCTG & lower \\
nd $1-85$ & AGTAGAACGAAAAGTCCTAG & upper \\
nd2-79| & TTAATTCTTGGATGATTATTC & lower \\
cox2-380 & ACTCCTATATAATCCCAACATCAG & upper \\
atp6-449 & GCTAGGGCTACTGGTTGAATAA & lower \\
atp6-301 & ACACCAACTACACAACTATCAATAA & upper \\
cox3-188 & CTTGGAAGGTGCTTTCTC & lower \\
cox3-205 & GAGAAAGCACCTTCCAAG & upper \\
cox3-717 & TCTACGAAATGTCAATATCAG & lower \\
nd $4-379$ & TCCTATTTGAAGCAACACTAG & upper \\
nd $4-804$ & ATTGAGCTGGTTATAATTATG & lower \\
nd5-767 & CTCAAGCACAATAGTAGTAGCAGG & upper \\
cytb-830 & ATTGATCGTAAGATTGCGTATG & lower \\
cytb-4l9 & CCATGAGGACAAATATCATT & upper \\
cytb- 1001 & CCTCCAATTCATGTGAGTG & lower \\
\hline
\end{tabular}

aThe numbers refer to the position of PCR primers (3') in mitochondrial genes.

\section{Non-coding sequences}

Among vertebrate mitochondrial genomes, most of the non-coding sequences are part of the control region, about 700-1,300 bp in length, responsible for the regulation of replication and transcription [10]. The control region shows extensive variability across taxonomic groups and even among related species, but its sequence elements related to regulatory functions are known to be



Figure I

The mitochondrial genome of $C$. bactrianus ferus ( $16,680 \mathrm{bp})$. Protein-coding genes (black) and rRNA genes (light-gray) are identified by arrows. The gene nd6 is transcribed in the opposite direction as relative to the rest in the cluster. tRNA genes are depicted with their corresponding amino acids. highly conserved. We annotated the 1,247-bp control region and regulatory domains; at the 5' end, we found termination-associated sequence (TAS) motifs that act as a signal for terminating synthesis of the D-loop strand $[11,12]$. The sequence between bactrian camel and alpaca showed less similarity as expected (Figure 3 ). We also discovered all eight putative conserved sequence blocks (CSB1-3 and B-F) that are important to the regulation of mtDNA replication [12]; among them, CSB1 and CSBC-F are conserved among mammals, whereas CSB2 and CSB3 are absent from some of them.

\section{Mitochondrial DNA variations in camelidae}

To investigate mitochondrial DNA variations in Camelidae, we compared the two complete sequences from the wild camel and alpaca; the comparison yielded 1,522 transitions and 389 transversions when excluding the highly variable control region. We also identified 26 single nucleotide indels (insertions or deletions) from noncoding RNA sequences. The most striking observation was a codon indel (GCC) encodes proline residue found in the nd1 gene between C. bactrianus ferus and L. pacos. This indel, upon further scrutiny, is actually an insertion in the L. pacos mtDNA but absolutely absent in the rest of mammalian mtDNA collection. In other words, it is lineagespecific to the New World L. pacos, suggesting that an insertion event occurred after the Old and New World Camelidae split. Furthermore, our comparative analyses showed a relatively lower ratio of nonsynonymous substitution $\left(\mathrm{K}_{\mathrm{a}}\right)$ to synonymous substitution $\left(\mathrm{K}_{\mathrm{s}}\right)$ in $\operatorname{cox} 1, \operatorname{cox} 2$, cox3, and $c y t b$ genes (Table 4$)$, whereas a large number of 
Table 2: Organization of Camelus bactrianus ferus mitochondrial genome

\begin{tabular}{|c|c|c|c|c|c|c|}
\hline Gene/element & Strand & Position & Start & Stop & Size & GC $\%$ \\
\hline tRNA-Phe & $\mathrm{H}$ & $1-67$ & - & - & 67 & 41.79 \\
\hline I $2 S$ rRNA & $\mathrm{H}$ & $68-1034$ & - & - & 967 & 43.54 \\
\hline tRNA-Val & $\mathrm{H}$ & $1035-1100$ & - & - & 66 & 38.57 \\
\hline I6S rRNA & $\mathrm{H}$ & $1101-2666$ & - & - & 1566 & 38.25 \\
\hline tRNA-Leu & $\mathrm{H}$ & $2667-2741$ & - & - & 75 & 42.67 \\
\hline ndl & $\mathrm{H}$ & $2745-3701$ & ATG & TAA & 957 & 45.24 \\
\hline tRNA-lle & $\mathrm{H}$ & $3701-3769$ & - & - & 69 & 30.43 \\
\hline tRNA-GIn & L & $3767-3839$ & - & - & 73 & 35.71 \\
\hline tRNA-Met & $\mathrm{H}$ & $384 I-3909$ & - & - & 69 & 45.25 \\
\hline$n d 2$ & $\mathrm{H}$ & $3910-4953$ & ATA & TAG & 1044 & 37.07 \\
\hline tRNA-Trp & $\mathrm{H}$ & $4966-5019$ & - & - & 54 & 43.24 \\
\hline tRNA-Ala & L & $5025-5093$ & - & - & 69 & 43.48 \\
\hline tRNA-Asn & L & $5095-5167$ & - & - & 73 & 39.21 \\
\hline OL & - & $5157-5211$ & - & - & 55 & 52.75 \\
\hline tRNA-Cys & L & $520 \mathrm{I}-5267$ & - & - & 67 & 40.58 \\
\hline tRNA-Tyr & L & 5268-5336 & - & - & 69 & 41.30 \\
\hline $\operatorname{cox} I$ & $\mathrm{H}$ & $5338-6885$ & ATG & TAG & 1548 & 44.12 \\
\hline tRNA-Ser & $\mathrm{L}$ & $6887-6957$ & - & - & 71 & 39.44 \\
\hline tRNA-Asp & $\mathrm{H}$ & $6962-7028$ & - & - & 67 & 40.68 \\
\hline $\cos 2$ & $\mathrm{H}$ & $7029-7712$ & ATG & TAA & 684 & 40.94 \\
\hline tRNA-Lys & $\mathrm{H}$ & $7716-7782$ & - & - & 67 & 47.76 \\
\hline atp8 & $\mathrm{H}$ & 7784-7987 & ATG & TAA & 204 & 34.80 \\
\hline atp6 & $\mathrm{H}$ & $7945-8625$ & ATG & TAA & 681 & 39.20 \\
\hline $\operatorname{cox} 3$ & $\mathrm{H}$ & $8625-9403$ & ATG & $\mathrm{T} \ldots$ & 779 & 47.75 \\
\hline tRNA-Gly & $\mathrm{H}$ & $9409-9478$ & - & - & 70 & 30.43 \\
\hline$n d 3$ & $\mathrm{H}$ & $9476-9825$ & ATA & TA & 350 & 43.14 \\
\hline tRNA-Arg & $\mathrm{H}$ & $9826-9893$ & - & - & 68 & 44.93 \\
\hline nd4l & $\mathrm{H}$ & $9894-10190$ & ATG & TAA & 297 & 40.74 \\
\hline nd4 & $\mathrm{H}$ & $10184-11570$ & ATG & $\mathrm{T} \ldots$ & 1387 & 42.39 \\
\hline tRNA-His & $\mathrm{H}$ & $11562-11630$ & - & - & 69 & 34.78 \\
\hline tRNA-Ser & $\mathrm{H}$ & $1 \mid 631-11689$ & - & - & 59 & 44.12 \\
\hline tRNA-Leu & $\mathrm{H}$ & $11691-11760$ & - & - & 70 & 39.73 \\
\hline nd5 & $\mathrm{H}$ & || $76|-1358|$ & ATA & TAA & $|82|$ & 41.30 \\
\hline nd6 & $\mathrm{L}$ & |3565-|4092 & ATG & TAA & 528 & 41.48 \\
\hline tRNA-Glu & L & $|4094-14| 62$ & - & - & 69 & 34.78 \\
\hline cytb & $\mathrm{H}$ & $14 \mid 67-15306$ & ATG & AGA & 1140 & 43.25 \\
\hline tRNA-Thr & $\mathrm{H}$ & $15307-15375$ & - & - & 69 & 34.80 \\
\hline tRNA-Pro & $\mathrm{H}$ & $15375-15440$ & - & - & 66 & 43.84 \\
\hline Control region & $\mathrm{H}$ & $|544|-\mid 6687$ & - & - & 1247 & 46.75 \\
\hline
\end{tabular}

$H$ and $L$ refer to heavy and light strains of the mitochondrial genome, respectively.

nonsynonymous substitutions were observed in $n d 2, n d 3$, $n d 4, n d 4 L$, and atp 6 gene sequences, especially in the atp 8 gene. This result indicates that the ND family and ATP synthase genes may evolve faster than other genes among the 13 protein-coding ones. This pattern is not universal among all mammalian mitochondrial genomes and suggests its functional relevance for mitochondrial biology. To our surprise, the $n d 1$ gene that harbors the codon insertion in $L$. pacos does not appear to have higher mutation rate as compared to other ND family genes in its mtDNA.

\section{Phylogenetic analyses}

To date the divergence time between Camelini and Lamini, we aligned complete mtDNA sequences of the wild camel and alpaca as well as other selected mammals. We then constructed a phylogenetic tree from these aligned sequences by using those of rat and mouse as outgroup (Figure 4). Since the control region of mtDNA has a high incidence of homoplasy $[5,13]$, we excluded it for this analysis. Similar topology was obtained with both neighbor-joining and maximum likelihood methods. Bootstrap values and Bayesian posterior probabilities were showed for all clades.

Estimating divergence time can be done with or without assuming a constant rate evolutionary rate among all compared clades. Since evolutionary rate of Camelidae mitochondrial genomes has not been well-studied, we tested the rate constancy in Camelidae using mtDNA excluding the control region. We first performed Tajima's 
Table 3: Comparison of codon usage among Camelus bactrianus ferus and selected vertebrates

\begin{tabular}{|c|c|c|c|c|c|c|c|c|c|}
\hline $\mathrm{AA}^{\mathrm{a}}$ & Codon & Camel & Alpaca & Dog & $\mathrm{AA}$ & Codon & Camel & Alpaca & Dog \\
\hline \multirow[t]{3}{*}{$\mathrm{G}$} & GGC & 67 & 63 & 51 & $M$ & ATA & 177 & 195 & 201 \\
\hline & GGA & 92 & 91 & 93 & & ATG & 75 & 58 & 47 \\
\hline & GGG & 36 & 30 & 28 & $D$ & GAT & 28 & 31 & 28 \\
\hline \multirow[t]{4}{*}{$A$} & GCT & 57 & 52 & 63 & & GAC & 41 & 42 & $4 I$ \\
\hline & GCC & 109 & 103 & 86 & E & GAA & 61 & 66 & 73 \\
\hline & GCA & 88 & 88 & 89 & & GAG & 35 & 28 & 21 \\
\hline & GCG & 12 & 9 & 14 & $\mathrm{~N}$ & AAT & 59 & 73 & 66 \\
\hline \multirow[t]{4}{*}{ V } & GTT & 46 & 43 & 49 & & $\mathrm{AAC}$ & 92 & 71 & 91 \\
\hline & GTC & 49 & 60 & 27 & $\mathrm{Q}$ & CAA & 67 & 78 & 68 \\
\hline & GTA & 80 & 84 & 65 & & CAG & 23 & 15 & 21 \\
\hline & GTG & 33 & 15 & 24 & $\mathrm{~K}$ & AAA & 77 & 83 & 81 \\
\hline \multirow[t]{6}{*}{ L } & TTA & 97 & 97 & 117 & & AAG & 19 & 18 & 19 \\
\hline & TTG & 32 & 15 & 28 & $\mathrm{R}$ & CGT & $7 c$ & 6 & 6 \\
\hline & СТT & 72 & 68 & 96 & & CGC & 14 & 16 & 10 \\
\hline & СТС & 97 & 93 & 90 & & CGA & 39 & 39 & 45 \\
\hline & CTA & $227^{b}$ & 279 & 230 & & CGG & 8 & 4 & 4 \\
\hline & CTG & 68 & 46 & 33 & $\mathrm{H}$ & CAT & 28 & 28 & 38 \\
\hline \multirow[t]{2}{*}{ I } & ATT & 179 & 167 & 174 & & CAC & 63 & 65 & 57 \\
\hline & ATC & 134 & 151 & 168 & $P$ & $\mathrm{CCT}$ & 54 & 43 & 64 \\
\hline \multirow[t]{4}{*}{$\mathrm{S}$} & $\mathrm{TCT}$ & 55 & 54 & 68 & & $\mathrm{CCC}$ & 81 & 84 & 62 \\
\hline & $\mathrm{TCC}$ & 75 & 69 & 74 & & $\mathrm{CCA}$ & 49 & 61 & 60 \\
\hline & $\mathrm{TCA}$ & 71 & 80 & 78 & & CCG & 12 & 10 & 7 \\
\hline & TCG & 10 & 8 & 12 & $\mathrm{~F}$ & TTT & 103 & 122 & 108 \\
\hline \multirow[t]{4}{*}{$\mathrm{T}$} & $\mathrm{ACT}$ & 60 & 70 & 75 & & TTC & 133 & 108 & 127 \\
\hline & $\mathrm{ACC}$ & 97 & 89 & 90 & $Y$ & TAT & 69 & 68 & 69 \\
\hline & $A C A$ & 126 & 142 & 120 & & TAC & 68 & 73 & 74 \\
\hline & ACG & 34 & 19 & 18 & w & TGA & 88 & 90 & 94 \\
\hline C & TGT & 11 & 9 & 4 & & TGG & 17 & 15 & 10 \\
\hline
\end{tabular}

a The one-letter code for amino acids (AA) was used;

$b$ the most frequently used codon;

$c$ the least frequently used codon.

relative rate test, using cow as an outgroup. Molecular clock analyses are highly sensitive to evolutionary distance between main clades and the choice of an outgroup is of importance [14]. The result rejected the assumption of a constant rate of change among the camelid mitochondrial genomes $(\mathrm{p}<0.01$, unpublished data). To further confirm this conclusion, we used likelihood ratio method for a similar test (Materials and Methods), and showed obvious differences in the evolutionary rate between the two tribes (without rate constancy LnL1 = 38557.259972; with rate constancy LnL2 = 38550.07554; $\mathrm{P}<0.01)$.

Since these studies pointed out that the assumption of rate constancy might not be appropriate for estimating divergence time between Camelini and Lamini, we used a heuristic rate smoothing procedure for ML-based estimates [15], which takes into account evolutionary rates among different branches of the tree. We used two calibration points, 65 and 14 million years, which were the esti- mated timing for the divergence of cow-pig (artiodactyl calibration) and mouse-rat (outgroup calibration), respectively $[16,17]$. Average rates for the wild camel and alpaca were $1.2 \%$ per million years and $0.9 \%$ per million years, respectively. Therefore, the divergence time between Camelini and Lamini was estimated to be 25 million years, significantly earlier than what was estimated based on fossil records (11 million years). This result suggested that the divergence of the two tribes might occur in the early Miocene $[2,4]$.

We also constructed a phylogenetic tree based on the $c y t b$ gene sequences from the wild camel and other camelids, and looked into other possibilities (Figure 5). Similarly, we used the two calibration points, 65 and 14 million years, and performed a maximum likelihood procedure to estimate divergence time. In tribe Camelini, the divergence time of bactrian camel and dromedary was estimated as 8 million years, whereas in tribe Lamini, alpaca diverged from the other three species about 10 million 

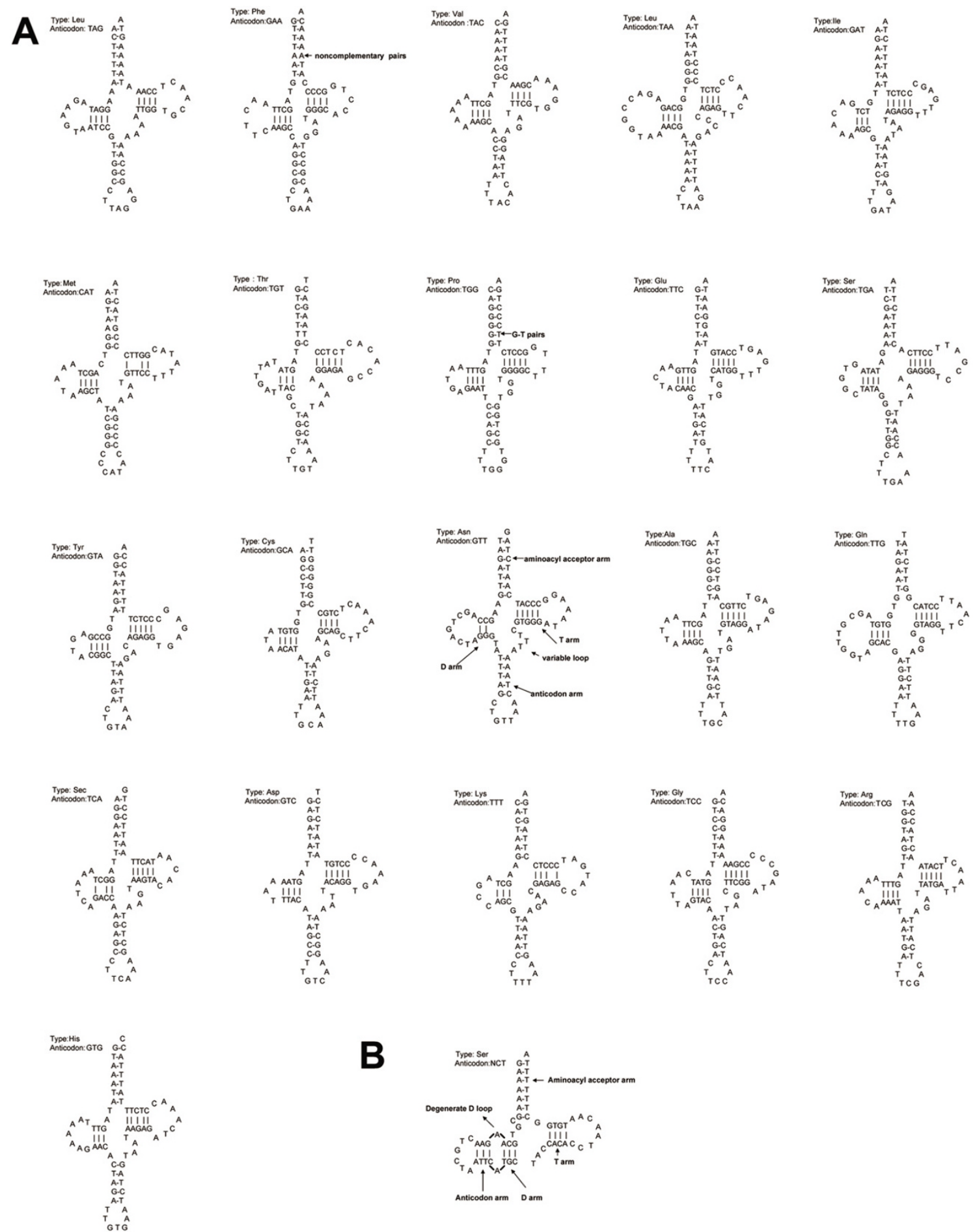

Figure 2

Predicted secondary structures of 22 mitochondrial tRNA sequences from the wild camel. All tRNAs were folded into secondary structures based on the "least free energy" principle. (A) 2I tRNAs exhibit cloverleaf structures and possess anticodons. The secondary structure of tRNAAsn was shown (bold) as an example for the cloverleaf structure that usually has 7 bp in the aminoacyl stems, 4 bp or 5 bp in the T $\psi \mathrm{C}$ and anticodon stems, and 4 bp or 3 bp in the DHU stems. tRNA stem regions include some non-complementary and T:G base pairings. (B) tRNAser can not form the appropriate dihydrouridine loop and does not possess the anticodon for AGN. 


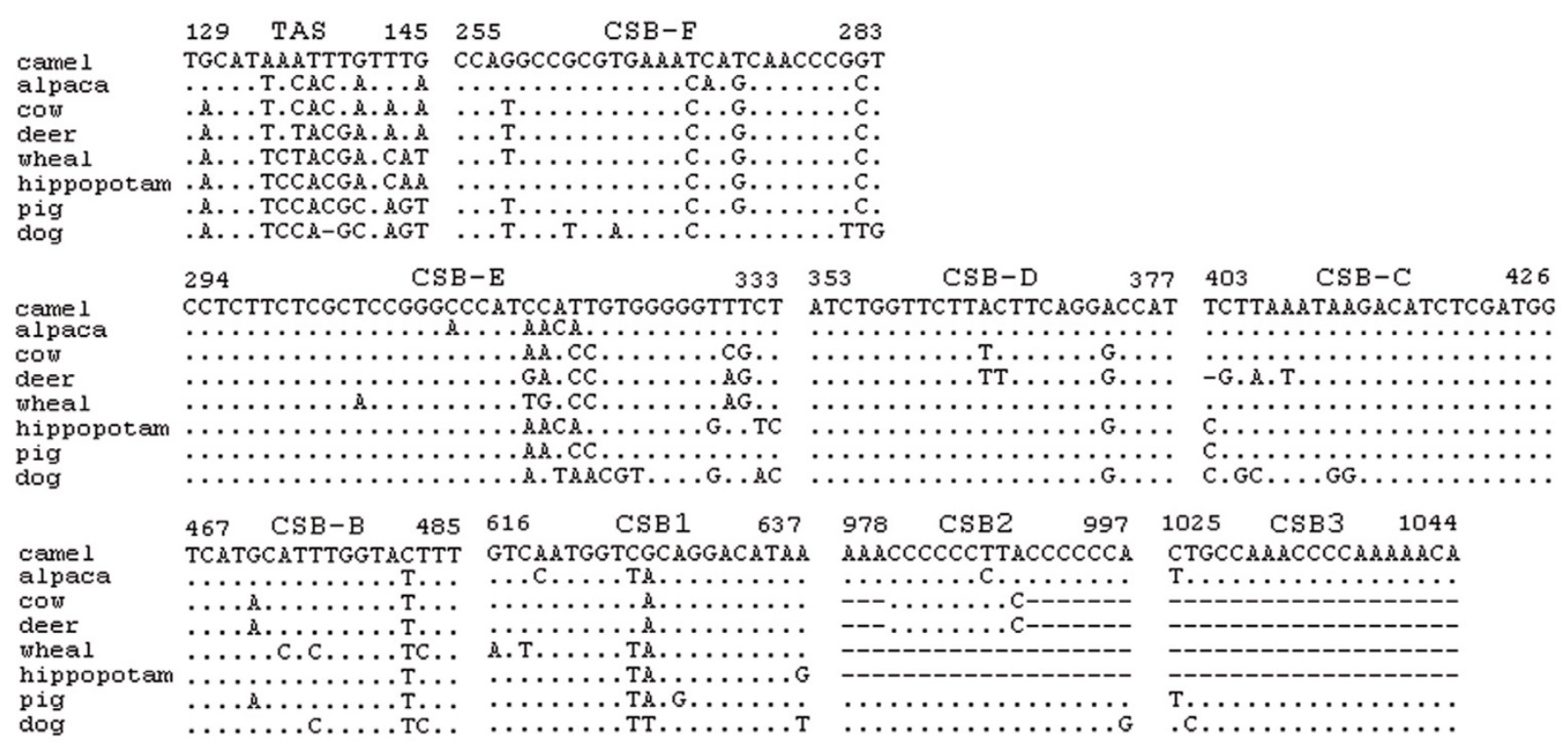

Figure 3

Alignment of termination-associated sequences (TAS) and eight putative conserved sequence blocks of CBS (I-3) and CBS (BF). The bactrian camel sequence was used as the consensus sequence, orientated from 5' to 3' on the heavy strand. Dots, dashes, and numbers indicate nucleotide identity, indels, and positions of the first and the last nucleotide for each identified region, respectively.

years ago. Guanaco and llama diverged from their common ancestor in the early Pleistocene, 1.4 million years ago.

\section{Discussion}

Although the mitochondrial genome of the wild twohumped camel is highly similar to those of other mammals, there are substantial differences in the mtDNA evolutionary rate for different taxonomic groups. Relative rate tests demonstrated the evolutionary rate also varies between bactrian camel and other mammals (Table 5). The difference within a taxonomic group is as significant as among groups. For example, the rate for bactrian camel is significantly different from that for alpaca, so does the rate between bactrian camel and cow.

The divergence time for Camelini and Lamini was estimated to be 25 million years or in the early Miocene. This estimate is significantly earlier than what were suggested based on the fossil record in North America [2,4]. In tribe

Table 4: The ratio of nonsynonymous substitution $\left(K_{a}\right)$ vs. synonymous substitution $\left(K_{s}\right)$ among the mitochondrial genes

\begin{tabular}{llll}
\hline Gene & $\mathrm{Ka}$ & $\mathrm{Ks}$ & $\mathrm{Ka} / \mathrm{Ks}$ \\
\hline nd6 & 0.056 & 1.248 & 0.045 \\
atp6 & 0.040 & 0.598 & 0.067 \\
atp8 & 0.162 & 0.557 & 0.290 \\
coxl & 0.009 & 0.866 & 0.010 \\
cox2 & 0.024 & 1.123 & 0.021 \\
cox3 & 0.026 & 1.601 & 0.016 \\
cytb & 0.051 & 1.271 & 0.040 \\
ndl & 0.023 & 1.847 & 0.012 \\
nd2 & 0.043 & 0.665 & 0.064 \\
nd3 & 0.063 & 0.929 & 0.068 \\
nd4 & 0.028 & 1.008 & 0.028 \\
nd4l & 0.040 & 0.874 & 0.046 \\
nd5 & 0.056 & 1.123 & 0.050
\end{tabular}




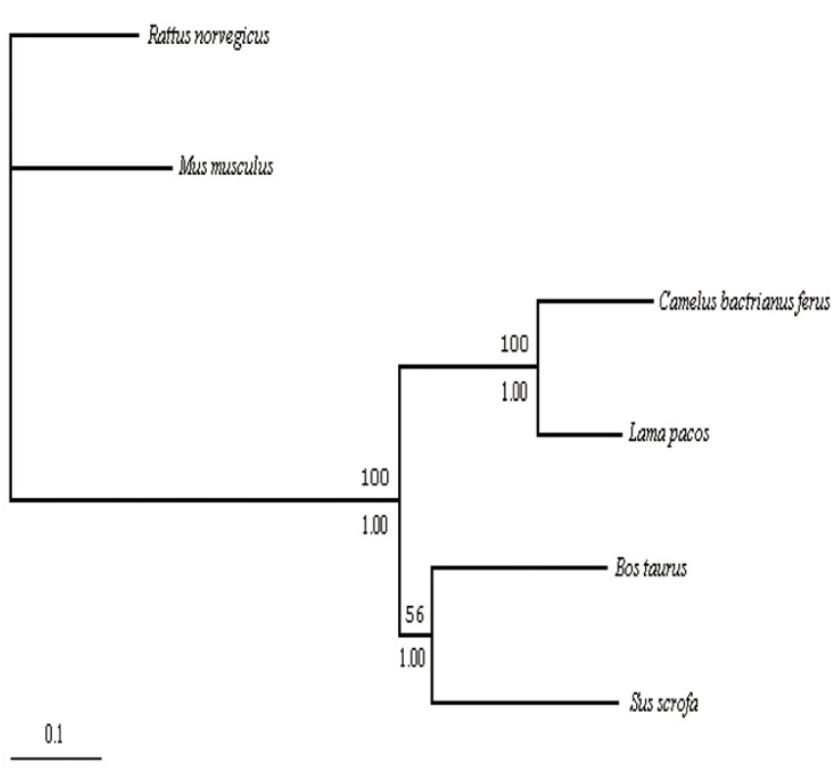

Figure 4

The phylogenic relationship between bactrian camel and alpaca based on maximum likelihood analysis (without the control regions). To estimate the divergence time, cow and pig were taken as an ingroup calibration point, while the mouse and rat were taken as an outgroup calibration point. All nodes were supported by the bootstrap value (1000 replications) and posterior probability on the nodes (above the branch is the bootstrap value, and below the branch is posterior probability). The scale bar indicates 0.1 substitutions.

Camelini, we estimated that speciation of bactrian camel and dromedary may have begun 8 million years ago. If the time of the camel migrating from North America to Asia estimated based on the fossil material is correct ( 3 million years) $[2,4]$, the speciation of the genus Camelus may

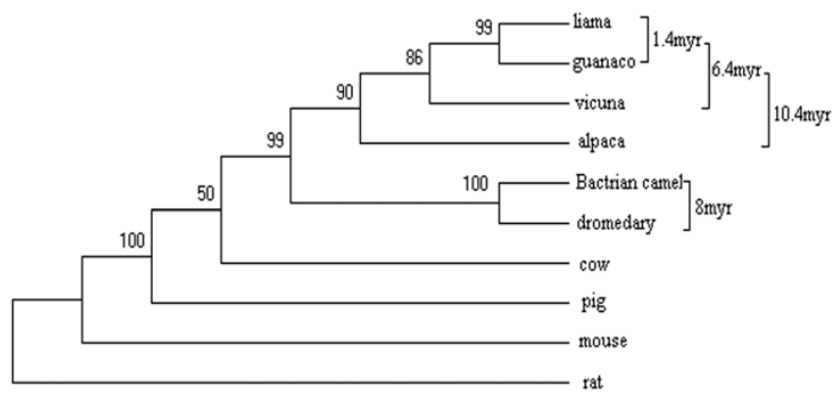

Figure 5

Phylogeny of the Camelidae species based on maximum likelihood analysis of cytb sequences. To estimate the divergence time, pairwise comparisons of cow-pig and mouse-rat were taken as the ingroup and outgroup calibration points, respectively. All nodes were supported by the bootstrap value ( 1000 replications) on the nodes. have occurred in North America. In tribe Lamini, alpaca is an older lineage that evolved to become the current species about 10 million years ago. In contrast, guanaco and llama diverged from their common ancestor much later, about 1.4 million years ago in the early Pleistocene; this divergence occurred after Lamini species migrated from North America to South America [2,4].

\section{Conclusion}

The mtDNA of C. bactrianus ferus is very similar to that of other mammals. It contains 13 protein-coding, two rRNA, and 22 tRNA genes as well as a typical control region. Molecular clock analyses on complete mitochondrial genomes from C. bactrianus ferus and Lama pacos suggested that the two tribes diverged from their common ancestor about 25 million years ago, much earlier than what were suggested based on fossil record. The evolutionary history of Camelidae, reconstructed by using $c y t b$ sequences, suggested that the speciation of bactrian camel and dromedary may have occurred in North America before they migrated to South America and subsequently left the continent.

\section{Methods}

\section{Specimens, DNA amplification, and sequencing}

The samples (ear punches) from the wild two-humped camel were collected in the Gobi area (the Trans-Altai Gobi of Mongolia as described by Sanduin 2002) of Mongolia in 2006. Genomic DNA was extracted according to the proteinase K/phenol extraction method. A PCR-Based approach for mitochondrial genome sequencing was used ([18]. The PCR primers used for initial amplification were designed based on conserved known mammalian sequences from the public databases, and new primers were also designed according to the newly generated sequence data for finishing the entire genome.

The standard PCR was conducted in a $25 \mu \mathrm{l}$ reaction volume that contains 1-2 U Taq DNA polymerase, $10 \mathrm{mM}$ Tris-HCl (pH 8.3), 0.25 mM dNTPs, 0.2-2 mM BSA, 1.5$2.5 \mathrm{mM} \mathrm{MgCl} 2,20 \mathrm{pM}$ of each primer, and about $10 \mathrm{ng}$ camel genome DNA. The PCR reaction conditions were set as: $94^{\circ} \mathrm{C}$ for the first $5 \mathrm{~min}$, followed by 35 cycles of $94^{\circ} \mathrm{C}$ denaturation for $30 \mathrm{~s}, 50^{\circ} \mathrm{C}$ annealing for $30 \mathrm{~s}$, and $72^{\circ} \mathrm{C}$ extension for $45 \mathrm{~s}$. The PCR were accompanied by negative controls containing the reaction solutions without DNA.

The thermo-cycling sequencing reaction was performed in a final volume of $24 \mu \mathrm{l}$ containing $16 \mu \mathrm{l}$ DYEnamic ET Terminator Sequencing Kit premix, 10 pM sequencing primers, and $500 \mu \mathrm{g}$ DNA. The reaction conditions were $95^{\circ} \mathrm{C}$ for $2 \mathrm{~min}$, followed by 35 cycles of $95^{\circ} \mathrm{C}$ denaturation for $15 \mathrm{~s}, 50^{\circ} \mathrm{C}$ annealing for $15 \mathrm{~s}$, and $60^{\circ} \mathrm{C}$ extension for $90 \mathrm{~s}$. The amplified DNA fragments were sequenced on ABI- 
Table 5: Relative rate test for pairs among vertebrate lineages

\begin{tabular}{cccc}
\hline Taxon pairs & Outgroup & $x^{2}$ & P \\
\hline $\begin{array}{c}\text { camel } \\
\text { alpaca } \\
\text { camel } \\
\text { cow } \\
\text { camel }\end{array}$ & cow & 16.87 & $<0.001$ \\
$\begin{array}{c}\text { pig } \\
\text { camel } \\
\text { deer } \\
\text { camel } \\
\text { whale }\end{array}$ & pig & 40.38 & $<0.001$ \\
\end{tabular}

3730 DNA sequencer. The primers for PCR reaction were used for sequencing. DNA sequences were assembled by using the software package phred/phrap/consed/[19,20] on a PC/UNIX platform. The mitochondrial sequences were annotated with BLAST tools, and tRNA genes and their secondary structures were identified according to tRNAscan-SE [21].

\section{Phylogenetic analysis}

The complete mitochondrial genome of $L$. pacos [GenBank:Y19184],Bos taurus [GenBank:AY526085], Sus scrofa [GenBank:AF034253], Mus musculus [GenBank:AY172335], Rattus norvegicus [GenBank:AY172581] and $c y t b$ gene sequences [GenBank:EF212038, GenBank:EF212037, GenBank:AY535258, GenBank:U06430, GenBank:U06429, GenBank:Y19184, GenBank:AY526085, GenBank: Bank:AY172335, GenBank:AY172581] used for phylogenetic analysis and other mammals used for comparison and PCR primer designs were obtained from the NCBI database. Multiple alignments were performed with the CLUSTAL W [22]. Alignments of all protein-coding genes were used to estimate variation rates at synonymous $\left(d_{S}\right)$ and nonsynonymous $\left(d_{N}\right)$ sites with a maximum likelihood (ML) method [15] implemented in Ka_Ks_Calculator [23].

The phylogenic trees were reconstructed separately according to the neighbor-joining method implemented in MEGA [24] and the maximum likelihood method implemented in PHYLIP [25]. The reliability of the branches was assessed by bootstrap analysis (1000 replications). Bayesian posterior probability of phylogeny was done with MrBayes (mcmc ngen = 1000000) [26]. Two different prior models were used: the General Time Reversible model and the HKY model.

Rate constancy was tested with the Tajima's [27] and likelihood ratio tests. The likelihood ratio test was done with the baseml program in PAML. Two parameters of no molecular (clock $=0$ in baseml) and the local clock (clock
= 2 in baseml) were used to test molecular clock. When bactrian camel and alpaca were tested, cow was used as outgroup. To estimate the divergence time, a heuristic rate smoothing procedure for ML estimates was used as implemented in PAML [15]

\section{Abbreviations}

$\operatorname{cox} 1, \cos 2, \operatorname{cox} 3$ - cytochrome oxidase subunit I, II, and III protein genes; atp6, atp 8 - ATP synthase subunit 6 and 8 genes; nad1, nad2, nad3, nad4, nad5, nad6, nad4L - NADH dehydrogenase subunit 1-6, 4L genes; $c y t b$ - cytochrome b gene; mtDNA- mitochondrial DNA; AA - amino acids.

\section{Authors' contributions}

HPZ and SNH were primarily responsible for the design and conducting this study. PC and FD were responsible for determining and assembling mtDNA sequences. RMTJ and JNG performed data analysis. PC and JY wrote the manuscript. HM and HWG were responsible for sample collection. All authors have read and approved the final manuscript.

\section{Acknowledgements}

We would like to thank the Department of Environment Sources in Mongolia for the permission for sample collections. The work was supported by the Synergic Project of Ministry of Environment and Resource of the Republic of Mongolia and Inner Mongolia Agricultural University of China for Conservation of Wild Bactrian Camels.

\section{References}

I. Novoa CM: Genetic Improvement of South American Camelids. Revta bras Genet 1989, 12:123-135.

2. Stanley HF, Kadwell M, Wheeler JC: Molecular evolution of the family Camelidae: a mitochondrial DNA study. Proceedings 1994, 256(I345): I-6.

3. Harrison JA: Revision of the Camelidae(Artiodactyla, Tylogoda) and description of the new genus Alforjas. PalaeontContr 1979, 95: I-20.

4. Webb SD: Pleistocene Llamas of Florida, with a brief review of the Lamini. In Pleistocene mammals of Florida Edited by: Gainesville . Florida , University press of Florida; 1974:170-214.

5. Ingman M, Kaessmann H, Paabo S, Gyllensten U: Mitochondrial genome variation and the origin of modern humans. Nature 2000, 408(68 I3):708-7I3.

6. Olivo PD, Van de Walle MJ, Laipis PJ, Hauswirth WW: Nucleotide sequence evidence for rapid genotypic shifts in the bovine mitochondrial DNA D-loop. Nature 1983, 306(5941):400-402. 
7. Ojala D, Montoya J, Attardi G: tRNA punctuation model of RNA processing in human mitochondria. Nature 198I, 290(5806):470-474.

8. Wolstenholme DR: Animal mitochondrial DNA: structure and evolution. Int Rev Cytol 1992, I41:173-216.

9. Chimnaronk S, Gravers Jeppesen M, Suzuki T, Nyborg J, Watanabe K: Dual-mode recognition of noncanonical tRNAs(Ser) by seryl-tRNA synthetase in mammalian mitochondria. Embo J 2005, 24(19):3369-3379.

10. Shadel GS, Clayton DA: Mitochondrial DNA maintenance in vertebrates. Annu Rev Biochem 1997, 66:409-435.

II. Clayton DA: Replication of animal mitochondrial DNA. Cell 1982, 28(4):693-705.

12. Clayton DA: Nuclear gadgets in mitochondrial DNA replication and transcription. Trends Biochem Sci |99|, I6(3): I07-III.

13. Bjornerfeldt S, Webster MT, Vila C: Relaxation of selective constraint on dog mitochondrial DNA following domestication. Genome Res 2006, I6(8):990-994.

14. Rogaev EI, Moliaka YK, Malyarchuk BA, Kondrashov FA, Derenko MV, Chumakov I, Grigorenko AP: Complete mitochondrial genome and phylogeny of Pleistocene mammoth Mammuthus primigenius. PLOS Biol 2006, 4(3):e73.

15. Yang Z: A heuristic rate smoothing procedure for maximum likelihood estimation of species divergence times. Acta Zoologica Sinica 2004, 50:645-656.

16. Springer MS, Murphy WJ, Eizirik E, O'Brien SJ: Placental mammal diversification and the Cretaceous-Tertiary boundary. Proc Natl Acad Sci U S A 2003, 100(3): I056-I06I.

17. Ursing BM, Arnason U: The complete mitochondrial DNA sequence of the pig (Sus scrofa). J Mol Evol 1998, 47(3):302-306.

18. Yamauchi MM, Miya MU, Machida RJ, Nishida M: PCR-based approach for sequencing mitochondrial genomes of decapod crustaceans, with a practical example from kuruma prawn (Marsupenaeus japonicus). Mar Biotechnol (NY) 2004, 6(5):419-429.

19. Ewing B, Green P: Base-calling of automated sequencer traces using phred. II. Error probabilities. Genome Res 1998 8(3): $186-194$.

20. Gordon D, Abajian C, Green P: Consed: a graphical tool for sequence finishing. Genome Res 1998, 8(3): 195-202.

21. Lowe TM, Eddy SR: tRNAscan-SE: a program for improved detection of transfer RNA genes in genomic sequence. Nucleic Acids Res 1997, 25(5):955-964.

22. Thompson JD, Higgins DG, Gibson TJ: CLUSTAL W: improving the sensitivity of progressive multiple sequence alignment through sequence weighting, position-specific gap penalties and weight matrix choice. Nucleic Acids Res 1994, 22(22):4673-4680.

23. Zhang Z, Li J, Yu J: Computing $\mathrm{Ka}$ and $\mathrm{Ks}$ with a consideration of unequal transitional substitutions. BMC Evol Biol 2006, 6:44

24. Kumar S, Tamura K, Nei M: MEGA3: Integrated software for Molecular Evolutionary Genetics Analysis and sequence alignment. Brief Bioinform 2004, 5(2): I50-163.

25. Felsenstein J: PHYLIP-phylogeny inference package (version3.2). Cladistcis 1989, 5:164-166.

26. Ronquist F, Huelsenbeck JP: MrBayes 3: Bayesian phylogenetic inference under mixed models. Bioinformatics 2003, | 9(12): 1572-1574.

27. Tajima F: Simple methods for testing the molecular evolutionary clock hypothesis. Genetics 1993, I35(2):599-607.

Publish with Bio Med Central and every scientist can read your work free of charge

"BioMed Central will be the most significant development for disseminating the results of biomedical research in our lifetime. "

Sir Paul Nurse, Cancer Research UK

Your research papers will be:

- available free of charge to the entire biomedical community

- peer reviewed and published immediately upon acceptance

- cited in PubMed and archived on PubMed Central

- yours - you keep the copyright
BioMedcentral 